\title{
Randomized controlled trial of emergency department initiated smoking cessation counselling and referral to a community counselling service
}

\author{
Ka Wai Cheung, MD, MPH*; lan WH. Wong, BSc*; Warren Fingrut, MD*; Amy Po Yu Tsai, MD*; \\ Sally R. Ke, MD*; Shayan Shojaie, MD*; Jeffrey R. Brubacher, MD*; Lauren C. Stewart, MPH*; \\ Shannon Erdelyi, MSc*
}

\begin{abstract}
Objective: Worldwide, tobacco smoke is still the leading cause of preventable morbidity and mortality. Many smokers develop chronic smoking-related conditions that require emergency department (ED) visits. However, best practices for ED smoking cessation counselling are still unclear.

Methods: A randomized controlled trial was conducted to determine whether an "ask, advise, and refer" approach increases 12-month, 30-day quit rates in the stable adult ED smoking population compared to usual care. Patients in the intervention group were referred to a community counselling service that offers a quitline, a text-based program, and a Web-based program. Longitudinal intention-to-treat analyses were performed.

Results: From November 2011 to March 2013, 1,295 patients were enrolled from one academic tertiary care ED. Six hundred thirty-five were allocated to usual care, and 660 were allocated to intervention. Follow-up data were available for $70 \%$ of all patients at 12 months. There was no statistically significant difference in 12-month, 30-day quit rates between the two groups. However, there was a trend towards higher 7-day quit attempts, 7 -day quit rates, and 30-day quit rates at 3,6 , and 12 months in the intervention group.

Conclusion: In this study, there was a trend towards increased smoking cessation following referral to a community counselling service. There was no statistically significant difference. However, if ED smoking cessation efforts were to provide even a small positive effect, such an intervention may have a significant public health impact given the extensive reach of emergency physicians.
\end{abstract}

\section{RÉSUMÉ}

Objectif: L'usage du tabac est encore la principale cause évitable de morbidité et de mortalité dans le monde. Bon nombre de fumeurs souffrent de maladies chroniques, liées au tabagisme, qui nécessitent des soins d'urgence. Toutefois, les pratiques exemplaires en matière de prestation de conseils en vue de l'abandon du tabac au service des urgences (SU) ne sont pas encore clairement établies.

Méthode: Un essai comparatif, à répartition aléatoire a été mené afin de déterminer si l'approche de type " demander, conseiller, orienter " permettrait d'augmenter le taux d'abandon durant 30 jours, sur une période de 12 mois, chez des fumeurs adultes, stables, traités au SU, comparativement aux soins usuels. Les patients dans le groupe expérimental ont été dirigés vers un service communautaire de guidance, qui offre un programme d'abandon du tabac soit par téléphone, soit par messages textes, soit sur le Web. Des analyses longitudinales selon le principe de vouloir traiter ont été réalisées.

Résultats: De novembre 2011 à mars 2013, 1295 patients ont participé à I'essai mené dans un SU universitaire de soins tertiaires : 635 d'entre eux ont été dirigés au hasard vers le groupe de soins courants, et 660, vers le groupe expérimental. Le groupe de chercheurs disposait de données de suivi sur $70 \%$ des patients, au bout de 12 mois. II n'y avait pas d'écart statistiquement significatif entre les deux groupes quant aux taux d'abandon durant 30 jours, sur une période de 12 mois. Toutefois, une tendance à la hausse a été observée en ce qui concerne les tentatives d'abandon durant 7 jours, les taux d'abandon durant 7 jours et durant 30 jours, au bout de 3, 6 et 12 mois dans le groupe expérimental.

Conclusion: Une tendance à la hausse a été observée, dans l'étude, en ce qui concerne l'abandon du tabac après que les sujets eurent été orientés vers un service communautaire de guidance, mais l'augmentation n'a pas atteint un écart statistiquement significatif. Toutefois, même si les efforts d'abandon de l'usage du tabac au SU ne se traduisaient que par un faible effet favorable, l'intervention pourrait avoir des retombées importantes en santé publique compte tenu du large accès auprès des urgentologues.

Keywords: emergency department, smoking cessation, public health

From the *Department of Emergency Medicine, Vancouver General Hospital, Faculty of Medicine, University of British Columbia, Vancouver, BC.

Correspondence to: Dr. Ka Wai Cheung, Vancouver General Hospital, 855 West 12th Avenue, Vancouver, BC V5Z 1M9; Email: tokwcheung@ gmail.com 


\section{INTRODUCTION}

Tobacco smoke is the leading cause of preventable deaths worldwide. ${ }^{1}$ Since 1998, the Society for Academic Emergency Medicine has recommended emergency department (ED) smoking cessation counselling. ${ }^{2}$ The American College of Emergency Physicians also recommends routine ED smoking cessation counselling. ${ }^{3}$ However, best practices for ED smoking cessation counselling have yet to be elucidated. Some advocates of ED smoking cessation counselling have recommended an "ask, advise, and refer" approach, where ED patients are asked whether they smoke, advised to quit, and then referred to an outpatient counselling service. ${ }^{4}$

The primary goal of this investigation was to determine whether brief ED-initiated counselling followed by referral to our provincial counselling service would increase 12-month, 30-day quit rates in medically stable adult smokers. A patient who had stopped using tobacco for 30 or more consecutive days prior to the 12-month phone call was deemed to have made a 12-month, 30 -day quit. Secondary outcomes included whether the intervention would increase 1-, 3-, and 6-month 30-day quit rates, as well as 1-, 3-, 6-, and 12-month, 7-day quit rates, quit attempts, and the use of smoking cessation therapies.

\section{METHODS}

\section{Study design}

A randomized controlled trial was conducted to determine whether a brief ED intervention of "ask, advise, and refer" would increase quit rates among stable adult ED patients. The study was approved by our institutional research ethics board and is registered under ClinicalTrials.gov, NCT01454375, where the full trial protocol can be accessed.

\section{Setting}

This study enrolled patients from the Vancouver General Hospital (VGH) ED from November 2011 to March 2013. VGH is a 700-bed, urban, adult tertiary-care teaching hospital, and the ED treats 85,000 patients annually. Prior to this study, emergency physicians did not routinely provide smoking cessation counselling. Our provincial community counselling service is funded by the government and offers a free confidential 24-hour quitline, as well as texting and Web-based services.

\section{Selection of participants}

All medically stable adult smoking patients ages 19 years and older presenting to the VGH ED who were able to provide informed consent in English were eligible for the study. A smoker was considered to be any individual who had used tobacco in the past 30 days. Patients were excluded if they could not provide informed consent, did not reside in British Columbia, or were unable to provide a telephone number for follow-up. During patient registration, patients were screened for study eligibility by the ED admitting clerks. Trained research assistants followed up on all potentially eligible patients identified by the admitting clerks. Enrolment and data collection were performed by the research assistants. All enrolled patients provided informed consent. Screening was performed 24 hours per day, 7 days per week.

\section{Interventions}

During the study period, ED-admitting clerks were advised to ask all presenting patients whether they had used tobacco in the last 30 days. If the patient answered "yes," a thick opaque study envelope was attached to the patient chart. Via these numbered opaque envelopes, all potentially eligible patients were randomized in a 1:1 fashion to either the usual care arm or intervention arm through block randomization generated by a random number table, with random block sizes of $2,4,6$, and 8 . Control envelopes were empty. Intervention envelopes contained a referral form to the community smokingcessation counselling service and a pamphlet advising the patient of available services.

Attending emergency physicians opened the study envelopes. Patients randomized into the control arm received no additional intervention or counselling outside of usual care. They were not informed of the community counselling service. Patients randomized into the intervention arm received a brief ED intervention that included receiving a pamphlet and an offer for a community counselling service referral. As part of the referral process, the emergency physician read the following statements verbatim to the patient, "Quitting smoking is the best thing you can do for your health. We know that many people who visit EDs want to quit smoking. [We have a community smoking cessation 
service that] is free in $\mathrm{BC}$, and they will help you quit smoking. I would like to refer you to [our community smoking cessation service]." This brief intervention took less than 30 seconds to complete. For all intervention patients who accepted, a referral was completed by the emergency physician and faxed to the community smoking cessation service. Patients were able to choose their preferred method of contact phone, text, and/or email. All patients were contacted by the community service within a week after receiving the referral. When intervention envelopes were not opened by the emergency physician, research assistants conducted the brief intervention and referral, either in the ED or in a follow-up phone call.

\section{Data collection and processing}

All data were collected by trained research assistants and double-entered into a Microsoft Excel spreadsheet (Microsoft Corporation, Richmond, VA). Baseline data were collected from all patients. Initial data collected included patient demographic information (age, gender), smoking history, baseline motivation to quit, knowledge and attitudes concerning smoking, current use of smoking cessation therapies, patient perception of whether their ED visit may be related to smoking, and final ED diagnosis and disposition. The smoking history included type of tobacco used, the number of cigarettes smoked daily (for cigarette smokers), years of smoking, and any previous 7-day quit attempts. Baseline motivation to quit was assessed by the patient's transtheoretical stage of change ${ }^{5}$ and self-efficacy. The transtheoretical stage of change model attempts to explain and predict behaviour by determining an individual's desire for change, ranging from precontemplation to contemplation, to preparation, to action, and then finally to maintenance. Self-efficacy was defined as the participants' self-reported confidence to quit smoking and was assessed on a scale of 1 to 10 , with 10 being "Most confident."

At 1, 3, 6, and 12 months after the index ED visit, all participants received follow-up phone calls from a research assistant. For all follow-up calls, the research assistant was blinded to whether the patient was randomized to the control or intervention arm. At follow-up, study participants were asked about their smoking status, including any successful cessation of tobacco use, any quit attempts made, and any current use of smoking cessation therapies. If patients had stopped using tobacco for 30 or more consecutive days prior to the phone call, they were deemed to have made a 30-day quit. If patients had stopped using tobacco for 7 or more consecutive days prior to the phone call, they were deemed to have made a 7-day quit. If patients were still smoking, they were asked if they had stopped smoking for any 7 consecutive days since the last phone call. An answer in the affirmative would qualify as a 7-day quit attempt. Patients were also asked about their current use of nicotine replacement therapy. At baseline and at each follow-up period, participants were called up to a maximum of 15 times. After the 12-month follow-up period was completed for all participants, the community service was contacted to determine which participants in the intervention arm enrolled and completed the program.

\section{Outcome measures}

Our primary research question was to determine whether there was a difference in 12-month, 30-day smoking cessation rates between the usual care and intervention arms. Between-group comparisons were also performed for secondary outcome measures, including 30-day smoking cessation rates at 1,3 , and 6 months, as well as 7 -day smoking cessation rates, quit attempts, and use of smoking cessation aids at $1,3,6$, and 12 months.

\section{Primary data analysis}

Categorical variables are presented as percentages, and numeric variables are presented as means \pm SD. Longitudinal intention-to-treat analyses were performed using generalized linear mixed effects models. All models included fixed effects for the intervention, time since the initial ED visit, and the interaction between time and the intervention. A random intercept was included for each subject. For each outcome measure, an adjusted model was fit that included age, gender, baseline motivation to quit, knowledge and attitudes towards smoking, baseline number of cigarettes smoked daily, number of years smoked, and patient perception that smoking was related to their ED visit as covariates. To better understand the impact of dropouts on our results, an attrition analysis was performed where all dropouts were assumed to be either smokers or non-smokers. A further regression analysis was performed to determine whether missing baseline information was related to the primary outcome. All analyses were performed using R v3.2.0 (R Foundation for Statistical Computing, Vienna, Austria). 
An initial sample size of 646 patients was calculated assuming a 30-day, 12-month quit rate of 3\% in the control group and $8 \%$ in the intervention group, with an alpha level of 0.05 and power of 0.8. Anticipating the possibility of a $50 \%$ loss to follow-up rate, our final target sample size was 1,292 patients.

\section{RESULTS}

Flow of patients through the study is demonstrated in the CONSORT diagram (Figure 1). Of 3,462 patients deemed to be potentially eligible, 1,295 were enrolled in the study. Of enrolled patients, 635 were allocated to usual care and 660 to the intervention. Of those patients randomized to the intervention arm, 412/660 (62.4\%) accepted a referral to our community service. The CONSORT diagram further details the number of patients who were lost to follow-up at $1,3,6$, and 12 months. All patients who had available data at any time point were included in the intention-to-treat analysis.

Baseline characteristics of participants are presented in Table 1. Our longitudinal analysis was adjusted for age, gender, baseline motivation to quit, knowledge and attitudes towards smoking, baseline number of cigarettes smoked daily, number of years smoked, and patient perception of whether their ED visit may be related to smoking. Table 2 presents the relationships between these baseline characteristics and primary and secondary outcomes.

Table 3 presents outcome data for both groups at 1, 3, 6, and 12 months. At 12 months, in the usual care arm, $18.1 \%$ had stopped smoking for 30 days continuously, and $21.7 \%$ had stopped smoking for 7 days continuously. At 12 months, in the intervention arm, 20.8\% had stopped smoking for 30 days continuously, and $24.9 \%$ had stopped smoking for 7 days continuously. Table 3 further shows the adjusted odds ratios for the intervention effect on all outcomes. There were no statistically significant differences in the odds of any outcome between the two groups.

The brief ED intervention and referral was completed by the emergency physician for $37 \%$ of all study participants. The remainder was completed by research assistants. There was no statistically significant difference in 1,3,6, and 12-month, 30-day quit rates between the group referred by emergency physicians and the group referred by research assistants.

Six percent $(77 / 1,295)$ of all study participants had missing baseline information. These subjects were excluded from the adjusted analysis because there were no statistically significant relationships between missing predictors and the primary outcome measure. An attrition analysis was performed where dropouts were assumed to be either smokers or non-smokers, and the intervention effect was similar for both analyses.

In total, $47.3 \%(195 / 412)$ of all intervention participants who agreed to a referral requested to be contacted by phone. The community service attempted to contact $95.4 \%(186 / 195)$ of those who requested a phone call. The remaining $4.6 \%$ of the referrals were lost in the system. Of those contacted by the community service, $62.4 \%(116 / 186)$ were successfully reached. Of those reached by phone, $46.6 \%$ (54/116) enrolled in the program, and $9.5 \%(11 / 116)$ completed the program. The community service was unable to provide details on whether patients who were texted or emailed were reached, because it could not be confirmed whether texts or emails were read by study participants.

\section{LIMITATIONS}

There were several important limitations to this trial. With respect to generalizability, this study was conducted at one tertiary care urban academic ED, and the results may not be generalizable to other EDs with different patient demographics. Furthermore, patients registering in the ED were screened for eligibility by admitting clerks with variable screening rates. We do not know how many eligible smokers were missed by the initial screening process. Furthermore, during the study period, 1,322 patients who were eligible were not enrolled, that is, about $50 \%$ of the eligible population. About half of these eligible patients declined the study, and half were not reachable by phone for enrolment. It is possible that those who were missed eligible patients and those who declined enrolment or were not reachable by phone may have different baseline characteristics from the patients who were enrolled in the study.

The intervention itself may also have biased the effect towards the null. As part of the screening process, patients were asked whether they had used tobacco in the last 30 days. Therefore, all enrolled patients essentially received the first step of the three-step "ask, advise, refer" intervention. Secondly, emergency physicians were aware that we were conducting a smoking study during this time period and may have been more likely to provide extra smoking cessation counselling to patients, whether they were in the intervention or usual care arms. All physicians 


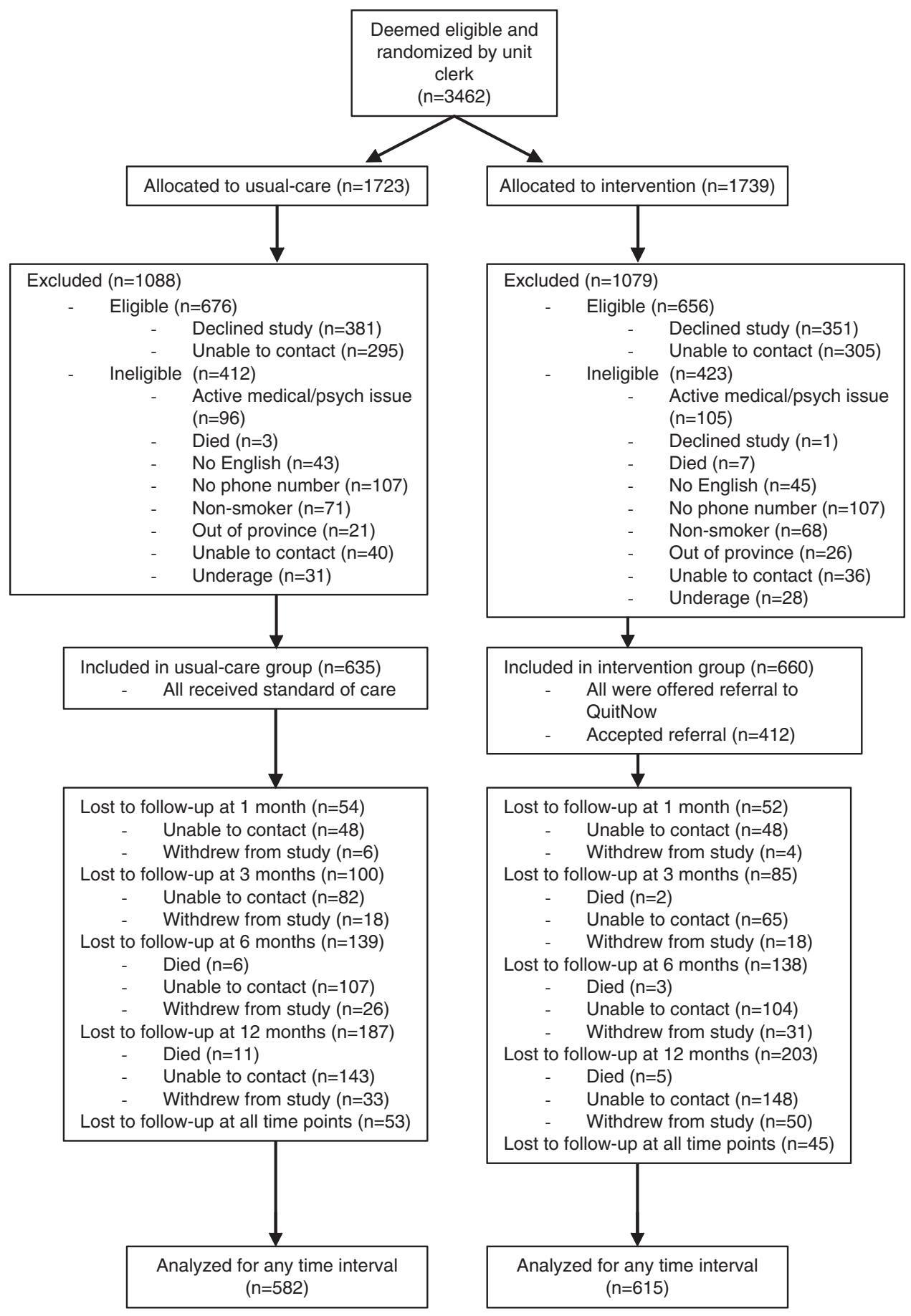

Figure 1. CONSORT diagram demonstrating flow of patients through study.

were advised to follow their usual practice; however, we did not follow up with usual care patients to determine what proportion received ED smoking cessation counselling. Asking usual care arm patients about whether they received ED smoking cessation counselling may have created even more bias. Finally, the 1-, 3-, 6-, and 12-month follow-up phone calls may have also increased quit rates amongst both the intervention and control groups. Although these phone calls were for data-gathering and no advice was offered, being questioned about tobacco use on a regular basis may increase quits. Although the effect of these follow-up phone calls would have been equal between the two groups, generally increasing quit rates in both arms would diminish the intervention effect. 
RCT of ED initiated smoking cessation counselling

\begin{tabular}{|c|c|c|}
\hline Characteristic & Usual care $(n=635)$ & Intervention $(n=660)$ \\
\hline Age in years, mean $( \pm S D)$ & $40( \pm 15)$ & $41( \pm 15)$ \\
\hline \multicolumn{3}{|l|}{ Gender, n (\%) } \\
\hline Male & $368(58)$ & $434(66)$ \\
\hline Female & $267(42)$ & $226(34)$ \\
\hline \multicolumn{3}{|l|}{ Smoking history, n (\%) } \\
\hline Has used tobacco in the last 7 days & $585(92)$ & $619(94)$ \\
\hline \multicolumn{3}{|l|}{ Type of tobacco used, n (\%) } \\
\hline Cigarette & $612(96)$ & $643(97)$ \\
\hline Cigar & $12(2)$ & $11(2)$ \\
\hline Other & $11(2)$ & $6(1)$ \\
\hline \multicolumn{3}{|l|}{ For cigarette smokers, average number of cigarettes smoked per day, $\mathrm{n}(\%)$} \\
\hline Light $(<10 /$ day $)$ & $322(51)$ & $316(48)$ \\
\hline Moderate (10-19/day) & $192(30)$ & $198(30)$ \\
\hline Heavy ( $\geq 20 /$ day) & $121(19)$ & $146(22)$ \\
\hline \multicolumn{3}{|l|}{ Average number of years smoked, $\mathrm{n}(\%)$} \\
\hline$\leq 5$ years & $95(15)$ & $91(14)$ \\
\hline $6-10$ years & $116(18)$ & $104(16)$ \\
\hline $11-15$ years & $98(15)$ & $76(12)$ \\
\hline 16-20 years & $58(9)$ & $77(12)$ \\
\hline$\geq 20$ years & $268(42)$ & $312(47)$ \\
\hline Has previously stopped smoking for 7 days continuously, $\mathrm{n}(\%)$ & $539(85)$ & $561(86)$ \\
\hline \multicolumn{3}{|l|}{ Transtheoretical stage of change } \\
\hline Precontemplation & $42(7)$ & $46(7)$ \\
\hline Contemplation & $372(59)$ & $385(59)$ \\
\hline Preparation/action & $217(34)$ & $225(34)$ \\
\hline \multicolumn{3}{|l|}{ Self-efficacy, mean $( \pm S D)$} \\
\hline How confident are you that you will not be smoking in 1 week? & $3.6( \pm 3.3)$ & $3.5( \pm 3.2)$ \\
\hline How confident are you that you will not be smoking in 6 months? & $6.1( \pm 3.0)$ & $6.1( \pm 3.1)$ \\
\hline \multicolumn{3}{|l|}{ Knowledge and attitudes, mean $( \pm S D)$} \\
\hline On a scale of $1-10$, how harmful is smoking to self? & $9.1( \pm 1.5)$ & $8.9( \pm 1.8)$ \\
\hline On a scale of $1-10$, how harmful is smoking to others? & $7.8( \pm 2.6)$ & $7.7( \pm 2.6)$ \\
\hline \multicolumn{3}{|l|}{ Smoking cessation therapy use, $\mathrm{n}(\%)$} \\
\hline Nicotine replacement therapy (lozenge, gum, patch, inhaler, spray) & $44(7)$ & $45(7)$ \\
\hline Prescription medication (bupropion or varenicline) & $8(1)$ & $4(1)$ \\
\hline Other & $7(1)$ & $17(3)$ \\
\hline None & $577(91)$ & $596(90)$ \\
\hline \multicolumn{3}{|l|}{ Do you believe that this ED visit is related to a smoking-related illness? $\mathrm{n}(\%)$} \\
\hline Yes & $72(12)$ & $74(11)$ \\
\hline No & $536(86)$ & $562(86)$ \\
\hline Maybe & $18(3)$ & $16(2)$ \\
\hline \multicolumn{3}{|l|}{ ED disposition } \\
\hline Discharged & $573(90)$ & $588(89)$ \\
\hline Admitted & $62(10)$ & $72(11)$ \\
\hline
\end{tabular}

All data collected were self-reported through faceto-face patient interviews and telephone follow-ups. Self-reported data, however, can correlate well with more objective measures, including exhaled carbon monoxide measurements ${ }^{6,7}$ and salivary and serum cotinine levels. ${ }^{7,8}$ We also did not audiotape the follow-up phone calls, but research associates were advised to follow a designated script for each call. During the course of the study, we encountered some loss to follow-up. At 12 months, we were able to follow up with $70 \%$ of our patients. This is similar to another ED smoking cessation study, where $65.6 \%$ of all patients were reached at 12 months. ${ }^{6} \mathrm{We}$ did 


\begin{tabular}{|c|c|c|c|c|}
\hline \multirow[b]{2}{*}{ Baseline characteristic } & \multicolumn{4}{|c|}{ Odds ratios $(95 \% \mathrm{Cl})$} \\
\hline & $\begin{array}{l}\text { 30-day smoking } \\
\text { cessation }\end{array}$ & $\begin{array}{l}\text { 7-day smoking } \\
\text { cessation }\end{array}$ & $\begin{array}{l}\text { At least one 7-day quit } \\
\text { attempt }\end{array}$ & $\begin{array}{l}\text { Use of any smoking } \\
\text { cessation aid }\end{array}$ \\
\hline Age (older versus younger) & $1.03(1.01,1.05)$ & $1.01(1.00,1.03)$ & $1.01(0.99,1.03)$ & $1.02(1.00,1.04)$ \\
\hline Male versus female & $1.65(1.02,2.65)$ & $1.68(1.10,2.55)$ & $1.86(1.25,2.77)$ & $0.77(0.50,1.18)$ \\
\hline $\begin{array}{l}\text { Baseline motivation to quit (higher versus lower } \\
\text { motivation) }\end{array}$ & $2.06(1.78,2.38)$ & $1.87(1.65,2.11)$ & $1.92(1.69,2.18)$ & $1.61(1.41,1.83)$ \\
\hline \multicolumn{5}{|l|}{$\begin{array}{l}\text { Baseline knowledge and attitudes (higher versus } \\
\text { lower sense of harm) }\end{array}$} \\
\hline Harmful to self & $0.90(0.77,1.06)$ & $0.92(0.80,1.05)$ & $0.99(0.86,1.12)$ & $1.21(1.04,1.40)$ \\
\hline Harmful to others & $1.17(1.05,1.30)$ & $1.11(1.01,1.22)$ & $1.08(0.99,1.18)$ & $0.94(0.86,1.03)$ \\
\hline \multicolumn{5}{|l|}{ Baseline daily smoking } \\
\hline Light versus heavy & $3.43(1.73,6.80)$ & $3.72(2.05,6.75)$ & $9.56(5.37,17.03)$ & $0.44(0.25,0.76)$ \\
\hline Moderate versus heavy & $0.97(0.47,2.01)$ & $0.90(0.48,1.68)$ & $1.30(0.72,2.33)$ & $1.27(0.74,2.15)$ \\
\hline $\begin{array}{l}\text { Number of years smoked (higher versus lower } \\
\text { years smoked) }\end{array}$ & $0.90(0.86,0.95)$ & $0.92(0.88,0.96)$ & $0.90(0.87,0.94)$ & $1.06(1.01,1.11)$ \\
\hline $\begin{array}{l}\text { Patient perception that ED visit was related to } \\
\text { smoking (yes versus no) }\end{array}$ & $1.30(0.66,2.58)$ & $1.17(0.63,2.16)$ & $1.19(0.65,2.15)$ & $1.18(0.66,2.11)$ \\
\hline
\end{tabular}

perform an attrition analysis where we assumed all dropouts to be either smokers or non-smokers, and there was no change in the intervention effect. Furthermore, we used all available data to estimate the intervention effect (not just 12-month data) with a mixed effects model, which is considered to be less biased, assuming data are missing at random. ${ }^{9}$

Finally, quitlines are available in all 10 provinces and 3 territories in Canada. All our study participants were referred to the British Columbia quitline. Our study was not designed to compare the effectiveness of the different quitlines. However, quitlines in Canada are quite similar, with most offering multi-session brief telephone interventions and similar Web-based services. ${ }^{10}$

\section{DISCUSSION}

Although our study did not find a statistically significant difference between the two groups with respect to the primary outcome, there was a trend towards increased 30-day quit rates, increased 7-day quit rates, and increased 7-day quit attempts in the intervention group at 3, 6, and 12 months (see Table 3). It has been noted that $p$-values have their own inherent limitations ${ }^{11}$ and that confidence intervals (CIs) showing effect sizes may be more meaningful. As in our study, this trend towards increased quit rates among the intervention group has been observed in other ED smoking cessation studies. ${ }^{6,12-15}$ A meta-analysis of seven ED smokingcessation interventions, including ED motivational interviewing, referral to outpatient smoking cessation programs, and booster calls showed increased quit rates at 1 month, with increased odds of quitting of 1.47 (95\% CI 1.06-2.06). ${ }^{16}$ More recently, an ED randomized controlled trial found an increased 3-month quit rate of $7.3 \%(95 \% \text { CI } 3.2-11.5)^{17}$ in their intervention group who received motivational interviewing, nicotine replacement therapy, a referral to a quitline, a booster call, and a brochure.

The definition of a smoker has varied in previous ED studies. In our study, we defined a smoker as someone who had used tobacco in the last 30 days. This was the most straightforward question for our admitting clerks to ask. Other definitions that have been used include 1) smoked on 1 or more days in the past 30 days $^{18}$; 2) answers "yes" to the question "Do you smoke?" 3) smoked 100 cigarettes in their lifetime and currently smokes cigarettes every day (daily) or some days (nondaily). ${ }^{17}$ As we defined a smoker as any individual who had used tobacco in the last 30 days, we then defined abstinence as any individual who had stopped using tobacco for 30 days. Furthermore, the majority of relapses happen within a month of the quit attempt. ${ }^{20}$ In addition to the 30-day abstinence, we also determined the conventional 7-day tobacco use abstinence and found that the intervention effect on 7-day abstinence and 30-day 


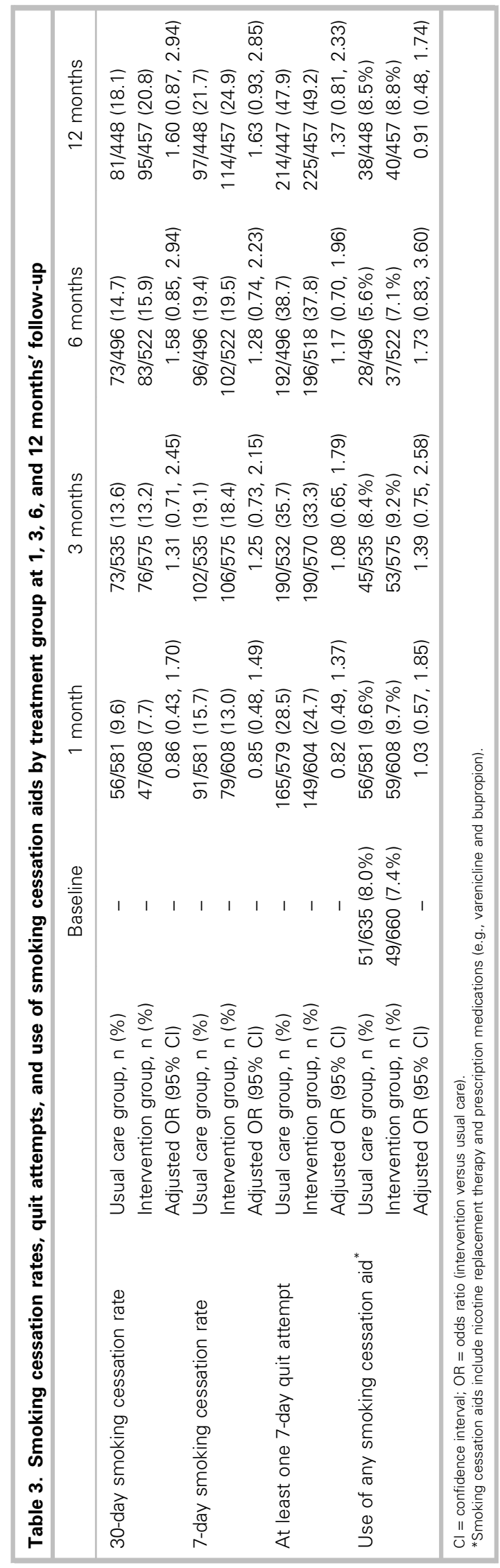

abstinence was similar. Finally, in our study, as we were following patients for 12 months, we wanted to assess more substantial quit attempts and therefore chose to use a 7-day quit attempt instead of the 24-hour quit attempt.

Overall, our study population was similar to previous ED smoking study populations. The average age was young, similar to other studies. ${ }^{21-23}$ It has been suggested that smokers may be reached more than 10 years earlier in the ED setting compared to the primary care setting, ${ }^{16}$ which is an important consideration in chronic disease prevention. In our study, more than $90 \%$ were in the contemplation, preparation, or action phases of change, which is in agreement with another study that found that approximately $70 \%$ of smokers wanted to quit and almost $50 \%$ wanted to do so within 1 month. ${ }^{24}$ Within the intervention group, $62.4 \%$ accepted a referral to the community counselling service. Out of those who requested a phone call, the community service was able to contact approximately $60 \%$, because the service is only allowed to call patients up to a maximum of three times. It is likely that an increased number of calls would have increased the quitline contact rate. ${ }^{25}$ Of those who were reached, approximately $50 \%$ enrolled in the program, and $20 \%$ of those who were enrolled completed the program. This intervention acceptance rate is in the range of previous studies. ${ }^{12,26}$

In our study, approximately one-third of patients received their brief ED intervention and referral from the emergency physician, and two-thirds received the intervention and referral from research assistants. Quit rates were not dependent on whether the intervention and referral were conducted by a physician or research assistant. This was likely because the intervention was brief, less than 30 seconds, and consisted of four sentences that were read verbatim to the patient. Therefore, there was very minimal variability in the intervention whether it was conducted by the emergency physician or research assistant.

\section{CONCLUSION}

Despite recommendations from the Society for Academic Emergency Medicine and the American College of American Physicians to provide ED smoking cessation counselling, best ED practices are still unclear. In this randomized controlled trial, there was no statistically significant difference in 12-month, 30-day quit rates between a control group and an intervention group that received a brief ED intervention followed by referral to 
our community smoking cessation service. However, there was a trend towards higher 7-day quit attempts, 7 -day quit rates, and 30-day quit rates at 3, 6, and 12 months in the intervention group. Given the extensive reach of emergency physicians, even a small positive effect may have a significant public health impact.

Acknowledgements: This study was funded by a Vancouver Coastal Health Research Institute Mentored Clinician Scientist Grant (KC). Funding was also received from the British Columbia Ministry of Health, the British Columbia Lung Association, and the British Columbia Cancer Agency.

Competing interests: None declared.

\section{REFERENCES}

1. WHO. Tobacco. WHO Media Centre; 2015.

2. Rhodes KV, Gordon JA, Lowe RA. Preventive care in the emergency department, part I: clinical preventive services are they relevant to emergency medicine? Society for Academic Emergency Medicine Public Health and Education Task Force Preventive Services Work Group. Acad Emerg Med 2000;7(9):1036-41.

3. Bernstein SL, Boudreaux ED, Cydulka RK, et al. Tobacco control interventions in the emergency department: a joint statement of emergency medicine organizations. Ann Emerg Med 2006;48(4):e417-26.

4. Schroeder SA. What to do with a patient who smokes. 7AMA 2005;294(4):482-7.

5. Spencer L, Pagell F, Hallion ME, et al. Applying the transtheoretical model to tobacco cessation and prevention: a review of literature. Am $\mathcal{F}$ Health Promot 2002;17(1):7-71.

6. Neuner B, Weiss-Gerlach E, Miller P, et al. Emergency department-initiated tobacco control: a randomised controlled trial in an inner city university hospital. Tob Control 2009;18(4):283-93.

7. Bernstein SL, Bijur P, Cooperman N, et al. A randomized trial of a multicomponent cessation strategy for emergency department smokers. Acad Emerg Med 2011;18(6):575-83.

8. Vartiainen E, Seppala T, Lillsunde P, et al. Validation of self reported smoking by serum cotinine measurement in a community-based study. 7 Epidemiol Community Health 2002;56(3):167-70.

9. Sterne JAC, White IR, Carlin JB, et al. Multiple imputation for missing data in epidemiological and clinical research: potential and pitfalls. BM7 2009;338:b2393.

10. North American Quitline Consortium. Promoting evidence based quitline services across diverse communities in North America; 2017. Available at: http://www.naquitline.org/? page $=$ aboutquitlines (accessed 15 March 2017).
11. Chavalarias D, Wallach JD, Li AH, et al. Evolution of reporting p-values in the biomedical literature, 1990-2015. 7AMA 2016;315(11):1141-8.

12. Schiebel NE, Ebbert JO. Quitline referral vs. self-help manual for tobacco use cessation in the emergency department: a feasibility study. BMC Emerg Med 2007;7:15.

13. Bernstein SL, Boudreaux ED, Cabral L, et al. Nicotine dependence, motivation to quit, and diagnosis among adult emergency department patients who smoke: a national survey. Nicotine Tob Res 2008;10(8):1277-82.

14. Katz DA, Holman JE, Nugent AS, et al. The Emergency Department Action in Smoking Cessation (EDASC) Trial: impact on cessation outcomes. Nicotine Tob Res 2013;15 (6):1032-43.

15. Boudreaux ED, Baumann BM, Perry J, et al. Emergency department initiated treatments for tobacco (EDITT): a pilot study. Ann Bebav Med 2008;36(3):314-25.

16. Rabe GL, Wellmann J, Bagos P, et al. Efficacy of emergency department-initiated tobacco control - systematic review and meta-analysis of randomized controlled trials. Nicotine Tob Res 2013;15(3):643-55.

17. Bernstein SL, D'Onofrio G, Rosner J, et al. Successful tobacco dependence treatment in low-income emergency department patients: a randomized trial. Ann Emerg Med 2015;66(2):140-7.

18. Horn K, Dino G, Hamilton C, et al. Efficacy of an emergency department-based motivational teenage smoking intervention. Prev Chronic Dis 2007;4(1):A08.

19. Antonacci MA, Eyck RT. Utilization and effectiveness of an emergency department initiated smoking cessation program. Acad Emerg Med 2000;7(10):1166.

20. Hughes JR, Keely J, Naud S. Shape of the relapse curve and long-term abstinence among untreated smokers. Addiction 2004;99(1):29-38.

21. Boudreaux ED, Kim S, Hohrmann JL, et al. Interest in smoking cessation among emergency department patients. Health Psychol 2005;24(2):220-4.

22. Bock BC, Becker B, Monteiro R, et al. Physician intervention and patient risk perception among smokers with acute respiratory illness in the emergency department. Prev Med 2001;32(2):175-81.

23. Bock BC, Becker B, Niaura R, et al. Smoking among emergency chest pain patients: motivation to quit, risk perception and physician intervention. Nicotine Tob Res 2000;2(1):93-6.

24. Lowenstein SR, Tomlinson D, Koziol-McLain J, et al. Smoking habits of emergency department patients: an opportunity for disease prevention. Acad Emerg Med 1995;2 (3):165-71.

25. Gordon JS, Andrews JA, Crews KM, et al. The 5A's vs 3A's plus proactive quitline referral in private practice dental offices: preliminary results. Tob Control 2007;16(4):285-8.

26. Anders ME, Sheffer CE, Barone CP, et al. Emergency department-initiated tobacco dependence treatment. $A m \mathcal{F}$ Health Behav 2011;35(5):546-56. 